\title{
AN EXPERIMENTAL STUDY TO INVESTIGATE THE IMPACT OF IMAGE INERACTIVITY ON THE PERCEPTION OF LUXURY IN AN ONLINE SHOPPING CONTEXT
}

\begin{abstract}
The current study investigates whether image interactivity can positively influence luxury perceptions in a virtual shopping environment, by offering shoppers a feeling of telepresence. 185 respondents were referred to either an image interactive or non-interactive virtual luxury store and completed an online questionnaire afterwards to measure their luxury perception. The results of this study show that image interactivity leads to higher perceptions of exclusivity, quality, hedonism and extended self due to a higher perceived telepresence. This study offers some guidelines for luxury brands to retain their luxury perception high in a virtual shopping environment.
\end{abstract}

\section{INTRODUCTION}

The Internet has become an indispensable part of the current corporate world. Consequently, online shopping became inseparable from today's society. When shopping online, consumers expect a website with the most optimal package of advantages, values and experiences. Products sold on the internet are only one click away from the consumer and available regardless of time and space (Okonkwo, 2009). Because of the supplementary profits (Geerts, 2013) and the general trend towards convenience (Hennigs, Wiedmann, Klarmann, \& Behrens, 2015), it became desirable and even unavoidable for luxury houses to exhibit their brands online. The online environments in which these brands are present vary from social network sites, online informational websites or actual webstores (Hennigs, Wiedmann, \& Klarmann, 2012; A. J. Kim \& Ko, 2012). These trends seem to be in favour of the online sales of luxury goods, knowing a strong year-on-year growth of approximately 30 percent and have even grown twelvefold in the past 11 years (D'Arpizio, Levato, Zito, \& de Montgolfier, 2014; The luxury and cosmetics financial factbook, 2015). Due to this rapid growing pace, the question is no longer 'whether' but 'how' to sell online as a luxury brand. The online shopping of luxury goods as well as non-luxury goods, have previously raised some concerns, for example, regarding the lack of touch or trained staff (Kluge \& Fassnacht, 2015; Pappas, 2016). An additional worry that specifically accounts for the online sale of luxury goods is the incompatibility of the exclusive luxury aura and the ubiquitous character of the internet (Hyeonsoo Kim, Choi, \& Lee, 2015). As luxury perceptions about product quality and uniqueness have been shown to affect outcomes such as buying behaviour (Hennigs et al., 2015), it is a key challenge for luxury brands to reassure their values online. The aim of the current study is therefore to investigate how luxury retailers can optimize their online presence and preserve their highly valued luxury perception. Previous studies provide an initial glimpse at how the interactive character of websites affect the growing wish to surf and shop online, the attitude towards the online retailer and the return to a website (Fiore \& Jin, 2003; Li, Daugherty, \& Biocca, 2001; Wu, 1999). The current study will build thereon, by investigating whether online image interactivity affects the actual luxury perception of consumers. Accordingly, this experimental study aims to find out whether image interactivity can compensate the lack of certain visual and tactile experiences online and add value to the luxury brand. Depending on the degree of interactivity, the quality and quantity of the simulated sensory experience may be affected, which can subsequently induce a feeling of 'telepresence' (Fiore, Kim, \& Lee, 2005). This concept can be defined as a "feeling as if he or she is with a physical product or perception of no difference between a physical 
and a virtual product" (Li et al., 2001, p.22). The current study will investigate how image interactivity affects luxury perceptions while online shopping and whether this effect would be mediated by a feeling of telepresence. To answer these questions a thorough review of the existing academic literature will be presented, and based thereon, an experimental research will be designed and conducted. The results will be presented, and to conclude the managerial implications will be discussed.

\section{THEORETICAL FRAME AND HYPOTHESIS CONSTRUCTION}

\section{Luxury Perception and its Sub Dimensions}

The desire to buy and the actual consumption of luxury brands stems from several dimensions of perceived values and consumer perceptions (Hennigs et al., 2015; Vigneron \& Johnson, 2004; Wiedmann, Hennigs, \& Siebels, 2007, 2009). To measure the luxury perception of consumers, previous research provided theoretical frameworks to divide the value evoked by luxury products into different sub dimensions (Vigneron \& Johnson, 1999, 2004; Wiedmann et al., 2007). These dimensions seek to explain the consumption behaviour of luxury products. Conspicuousness dimension refers to the fact that consumers consider the opinions of reference groups when publicly consuming luxury products (Vigneron \& Johnson, 2004). The Uniqueness dimension is based on the assumption that perceptions of exclusivity and rareness intensify the desire for a product or brand. The quality dimension argues that people expect luxury brands to deliver superior product quality in comparison with non-luxury brands (Vigneron \& Johnson, 2004). The hedonic dimension comprises of the expected emotional reactions as sensory pleasure, aesthetic beauty and excitement that is experienced by the consumer, while consuming luxury. The extended self dimension relates to the personal orientation of the consumer whereby (s)he uses the luxury goods to develop or support his/her own identity (Wiedmann et al., 2007). One might expect that the democratization of the online world contradicts with products that are defined by the above mentioned characteristics. However, due to the continuous growth of the luxury sector, an evolution towards mass marketing practices and online sales is observed (Chandon, Laurent, \& Valette-Florence, 2016). Therefore, more than ever, it is important for luxury brands to retain the perceived luxury value of their brand high, while achieving high returns. Particularly when shopping online, consumers cannot feel, touch and experience the luxurious store environment, which is an important asset for luxury retailers (Joy, Wang, Chan, Sherry, \& Cui, 2014). Therefore we aim to investigate how the luxury brand can be presented most successfully online, while retaining a high luxury perception.

\section{Appealing to the Senses in Online Luxury Retail}

In the bricks and mortar store, consumers get information about the shape, texture and perceived function of a product by examining it with their senses (Li, Daugherty, \& Biocca, 2002). As the shopping atmosphere is seen as the key element to a successful sale, more and more online retailers also aim to offer the optimal package of advantages, values and experiences for the consumer (Mankodiya et al., 2013). This especially accounts for luxury brands, who's success highly relies on the calibrated atmosphere of the stores and the related sensory experiences (Okonkwo, 2010). When shopping for products, many decisions are made based on the tactile experience. Consumers try to shape an image about the weight of the product and how it would feel to use the product by touching it (Soars, 2009). However, this sense is difficult to be transformed within the virtual environment. Therefore, retailers try to visualise online products as accurately as possible so we 
can more or less get an idea of how it would be like if we would feel the product with our own hands (Okonkwo, 2010).

\section{Online Image Interactivity as a Compensation For Sensory Loss}

Image interactivity offers an innovative way to present products, emphasizing their attributes and simulating a real product experience within the virtual world (Kim et al., 2007). Examples of image-interactive technologies that are used by online retailers include zoom-in functions, mixand-match functions, colour swapping and 3D technologies (Kim et al., 2007). Empirical evidence emphasizes the importance of image interactivity in favour of consumer attitudes and behaviour (e.g. Altarteer et al., 2013; Fiore \& Jin, 2003; J. Kim et al., 2007; Li et al., 2001). The use of image interactivity offers a feeling of control, as there is more product interaction and information present, which is necessary to make a well-informed choice (Fiore, Jin, et al., 2005). The characteristics of image interactivity result in a shopping experience characterised by rich product information and in cognitive processes (like control), pleasure and involvement (Li et al., 2001). Interactive images could help the consumer to make an estimation about the tactile and visual quality of the product and could therefore possibly affect the consumer's luxury perceptions.

\section{The Mediating Role of Telepresence}

Online simulations of shopping environments and products, represent mental images that consumers traditionally see in bricks and mortar stores. This provides them the sensation and the feeling "to be there" with a product (Li et al., 2001). Telepresence is created through interaction with a website, and is described as the feeling to be transported to another location or the feeling to be present in a mediated space that is different from the one where your physical body is present (Klein, 2003; Li et al., 2001). The direct experience of reality is defined as 'presence', whereas 'telepresence' is the simulated perception of the direct reality (Coyle \& Thorson, 2001; Klein, 2003). Steuer (1992) distinguishes two important dimensions of telepresence. First, vividness, refers to the ability of a technology to produce sensory, rich and mediated environments. Secondly, Interactivity, refers to the degree wherein the users of a certain medium can manipulate its shape or content. Vividness as well as interactivity are essential elements to create a feeling of telepresence that is strong enough to influence consumers' attitudes towards a product (Fiore, Jin, et al., 2005). An interactive website does not only offer the consumer a feeling of control, it also presents the products with a higher level of vividness compared to a non-interactive website (Fiore, Jin, et al., 2005). Based on the previous, we expect interactive features to positively affect telepresence. The higher the level of telepresence, the richer the online shopping experience will be. It is thus reasonable to expect that it is easier for the consumer to estimate the value of product aspects such as quality and uniqueness, when there is a high compared to a low level of telepresence. Based on this we constructed the following hypothesis:

\section{Hypothesis 1: Image interactivity will lead to a higher luxury perception compared to the control condition, and this effect is mediated through a feeling of telepresence.}

\section{The Impact of Image Interactivity on the Perceived Quality}

A high level of involvement, that can be obtained by using interactive website features, makes sure the consumer pays more attention to a product and provides the consumer with elaborate product information (Celsi \& Olson, 1988). Li and colleagues (2001) conducted a study where respondents had to analyze products through image interactive technology. They observed that all respondents made at least one remark about a specific part of the products. The strong attention to details and 
particularities suggests that the virtual experience generates active thinking patterns about products and their attributes. According to Kim and Lennon (2010), zoom-in features enable consumers evaluate the structure of the used material, its quality and other details while online shopping. We believe that the feeling to be somewhere and to actually interact with a product (e.g. Biocca, 1997; Coyle \& Thorson, 2001; Klein, 2003), combined with the increase of perceived information (Kim \& Lennon, 2010) will consequently result in higher perceptions of quality.

Hypothesis 1a: Image interactivity will lead to a higher perceived quality value compared to control and this effect is mediated by a feeling of telepresence.

\section{The Impact of Image Interactivity on the Perceived Hedonic Value}

An online shopping experience can result into utilitarian as well as hedonic values (Scarpi, Pizzi, \& Visentin, 2014). The hedonic value is described as the obtained pleasure while shopping (Demangeot \& Broderick, 2007). From several empirical studies, it appears that image interactivity positively influences the degree of fun while online shopping (Fiore, Jin, et al., 2005; Kim et al., 2007). This implies that interaction itself can provide hedonic value. When telepresence increases as a result of image interactivity, the pleasure obtained through sensory information will rise as well (Fiore, Jin, et al., 2005). Based on this, we can hypothesize that the higher perceived telepresence derived from image interactivity, could imply higher amounts of pleasure and thereby perceived hedonic value.

Hypothesis 1b: Image interactivity leads to a higher perceived hedonic value compared to control and this effect is mediated by a feeling of telepresence.

\section{The Impact of Image Interactivity on the Perceived Extended Self}

By purchasing luxury products, consumers are trying to convey the symbolic value of the brand on their own identity (Vigneron \& Johnson, 2004). Consumers use their luxury products to communicate their identity to significant others and see these possessions as an extension of their self (Hudders, 2011). 93\% of participants in the research of Li and colleagues (2001) indicate experiencing a feeling of personal involvement while examining a product through image interactive technology. The possibility to be personally involved with a virtual product while using image interactive technology, makes us expect that a higher level of telepresence eases identification with the luxury brand or product, which in turn is expected to have an impact on the experienced extended self.

Hypothesis 1c: Image interactivity leads to a higher extended self value compared to control and this effect is mediated by a feeling of telepresence.

\section{The Impact of Image Interactivity on the Perceived Conspicuousness and Uniqueness}

Luxury products are often consumed in the search of social recognition and to obtain greater prestige or respect of significant others (Vigneron \& Johnson, 2004). The consumption of luxury goods with the motive to improve their position in society is also referred to as conspicuousness consumption (Hudders, 2011; Veblen, 1944). When offline shopping, the luxury product is purchased in a public setting, which goes along with high social visibility. However, when shopping online the social visibility decreases considerably, whether image interactive functions are available or not. Therefore we expect no difference for experienced conspicuousness when image interactivity is high versus low. Characteristics as exclusivity and scarcity are consistently linked 
to the concept of luxury in academic literature (Kapferer, 1998; Phau \& Prendergast, 2000; Vigneron \& Johnson, 2004). In an online shopping environment, luxury brands that are characterized by exceptionality and exclusivity are put on a medium with mass accessibility. We believe that image interactive functions could not compensate this strong paradox. Therefore we expect no difference for experienced uniqueness when image interactivity is high versus low.

--- FIGURE ONE ABOUT HERE ---

\section{Design}

\section{METHOD}

We examined the impact of image interactivity on luxury perceptions through an experimental study. More particularly, we tried to find a relation between the independent variable image interactivity, the mediating variable telepresence and the dependent variable luxury perception, including all its latent dimensions. The single factor between subjects design consisted of the following two conditions: image interactive vs. non-interactive technology.

\section{Stimulus Material}

Both male and female participants were exposed to a pair of shoes of the well-known brand Gucci. This brand was chosen, as its costly products are highly associated with luxury. The level of image interactivity was manipulated by replicating an existing website that uses image interactive technology, in a non-interactive way. On the interactive website (www.saksfifthavenue.com) the respondents had the possibility to freely explore the product through different image interactive technologies. The non-interactive website was exactly the same but did not provide any interactive tools. A pre-test (17 respondents, 10 women and 7 men) with a between-subjects experimental design revealed that the used stimulus material was actually perceived to be luxurious and interactive versus non-interactive.

\section{Procedure}

The participants were randomly assigned to one of the two conditions (interactive vs. noninteractive). Firstly the respondents were put through a number of socio-demographic questions to refer them, based on their gender, to the right pair of shoes. The respondents were instructed to analyse the pair of shoes on the website as they would do when actually purchasing the product. Subsequently all respondents were requested to fill in an online questionnaire. The data was collected through an online questionnaire, set up with Qualtrics.

\section{Measures}

Luxury perception was measured by 19 items of the Brand Luxury Index (BLI) scale of Vigneron and Johnson (2004; $\alpha=.64)$. Subsequently the level of telepresence was queried by a scale of Fiore, Kim and colleagues (2005), consisting of 5 items $(\alpha=.86)$.

\section{Participants}

185 respondents participated in the study. The average age of the respondents was 32 years, and the majority $(63.2 \%)$ was female $(n=117)$.

\section{The Mediating Role of Telepresence.}

\section{RESULTS}

The analysis (5,000 bootstrap samples; bias-corrected confidence intervals estimated and reported) revealed a significant indirect effect $(a b=.09, \mathrm{SE}=.04 ; 95 \% \mathrm{LLCI}=.0320,95 \% \mathrm{ULCI}=.1902)$. 
As predicted, image interactivity increased telepresence $(\mathrm{a}=.39, \mathrm{SE}=.12, \mathrm{t}(183)=3.38, \mathrm{p}=.001)$, which subsequently increased the luxury perception for the participants $(b=.24, \mathrm{SE}=.05, \mathrm{t}(182)=$ $4.58, \mathrm{p}=.000)$. Hypothesis 1 is thus supported. Next, we investigated the mediating role of telepresence for the effect of image interactivity on all latent dimensions of the luxury perception. An indirect effect on four of the five underlying dimensions of luxury perception was determined. Hypotheses 1a, 1b and 1c are supported since the effect of image interactivity on the quality (ab $=.09, \mathrm{SE}=.04 ; 95 \% \mathrm{LLCI}=.0320,95 \% \mathrm{ULCI}=.1902)$, hedonic $(\mathrm{ab}=.13, \mathrm{SE}=.05 ; 95 \% \mathrm{LLCI}$ $=.0470,95 \% \mathrm{ULCI}=.2516)$, and extended self $(\mathrm{ab}=.07, \mathrm{SE}=.04 ; 95 \% \mathrm{LLCI}=.0042,95 \% \mathrm{ULCI}$ $=.1861$ ) dimension is mediated by telepresence. What must be noted is that we could only detect a marginal significant effect of telepresence on the extended self dimension. As expected, there was no indirect effect found of image interactivity on the conspicuousness dimension through the mediator telepresence. However, contrary to expectations, a significant indirect effect of image interactivity on the uniqueness dimension was found through the mediator telepresence $(\mathrm{ab}=.15$, $\mathrm{SE}=.06 ; 95 \% \mathrm{LLCI}=.0577,95 \% \mathrm{ULCI}=.3081)$. So, the analysis of a product on a website with image interactive features ensures a higher degree of telepresence, in comparison with the analysis of the same product without these features. Telepresence in turn ensures a higher overall luxury perception, and a higher perception of quality, hedonism, extended self and, contrary to expectations, uniqueness.

\section{--- TABLE ONE ABOUT HERE ---}

\section{GENERAL DISCUSSION}

Despite the fact that the sensory experience while purchasing luxury products is of great importance (Kapferer, 1998; Okonkwo, 2005) and this aspect disappears for a great part when shopping online, it remained unclear whether online (image) interactivity could compensate this loss. The first goal of this research was to investigate if image interactive technology affects luxury perception and whether telepresence could be an underlying mechanism of this effect. As expected, an indirect effect of image interactivity on luxury perception was found through telepresence. The respondents analysing the pair of shoes through the image interactive website, having the possibility to zoom in on the product in detail, look at it through $360^{\circ}$ technology and adapt the colours, had a higher feeling of telepresence than those visiting the non-interactive website. This feeling of telepresence resulted in its turn into higher luxury perceptions, supporting hypothesis 1 . Furthermore, an indirect effect of image interactivity by telepresence was found on the sub dimensions quality, hedonism, and extended self, supporting the hypotheses. Besides, in contrast with our expectations, the results of this study revealed that image interactivity positively affects the uniqueness value of the product, through higher perceived telepresence. The feeling of telepresence might have really represent the direct physical experience for the participants, whereby the uniqueness factor that is usually associated with luxury products offline was also experienced online when using image interactive technology. This finding might be of great importance as many of the previous studies investigating online luxury consumption considered the incompatibility of the mass medium and the prestigious products as a threat for the luxury industry (Dall'Olmo Riley \& Lacroix, 2003; Kapferer, 2000; Okonkwo, 2010). However, these results could suggest that image interactive technology could help luxury brands preserve their highly valued uniqueness and prestige online, through a feeling of telepresence. To conclude, integrating image interactive technology on a luxury website offers a fruitful and promising tool for luxury brands to retain a high luxury value. 


\section{REFERENCES}

Altarteer, S., Charissis, V., Harrison, D., \& Chan, W. (2013). Interactive Virtual Reality Shopping and the Impact in Luxury Brands. In Virtual, Augmented and Mixed Reality. Systems and Applications (pp. 221-230). Springer. Retrieved from http://link.springer.com/chapter/10.1007/978-3-642-39420-1_24

Biocca, F. (1997). The Cyborg's Dilemma: Progressive Embodiment in Virtual Environments [1]. Journal of Computer-Mediated Communication, 3(2), 0-0.

Celsi, R. L., \& Olson, J. C. (1988). The role of involvement in attention and comprehension processes. Journal of Consumer Research, 210-224.

Chandon, J.-L., Laurent, G., \& Valette-Florence, P. (2016). Pursuing the concept of luxury: Introduction to the JBR Special Issue on "Luxury Marketing from Tradition to Innovation." Journal of Business Research, 69(1), 299-303.

Chen, S.-J., \& Chang, T.-Z. (2003). A descriptive model of online shopping process: some empirical results. International Journal of Service Industry Management, 14(5), 556-569.

Coyle, J. R., \& Thorson, E. (2001). The effects of progressive levels of interactivity and vividness in web marketing sites. Journal of Advertising, 30(3), 65-77.

Dall'Olmo Riley, F., \& Lacroix, C. (2003). Luxury branding on the Internet: lost opportunity or impossibility? Marketing Intelligence \& Planning, 21(2), 96-104.

D’Arpizio, C., Levato, F., Zito, D., \& de Montgolfier, J. (2014). Luxury Goods Worldwide Market Study Fall-Winter 2014. (pp. 1-36). Bain \& Company.

Demangeot, C., \& Broderick, A. J. (2007). Conceptualising consumer behaviour in online shopping environments. International Journal of Retail \& Distribution Management, 35(11), 878894.

Fiore, A. M., \& Jin, H.-J. (2003). Influence of image interactivity on approach responses towards an online retailer. Internet Research, 13(1), 38-48.

Fiore, A. M., Jin, H.-J., \& Kim, J. (2005). For fun and profit: Hedonic value from image interactivity and responses toward an online store. Psychology \& Marketing, 22(8), 669694.

Fiore, A. M., Kim, J., \& Lee, H.-H. (2005). Effect of image interactivity technology on consumer responses toward the online retailer. Journal of Interactive Marketing, 19(3), 38-53.

Geerts, A. (2013). Cluster analysis of luxury brands on the internet. International Journal of Management and Marketing Research, 6(2), 79-82.

Häubl, G., \& Trifts, V. (2000). Consumer decision making in online shopping environments: The effects of interactive decision aids. Marketing Science, 19(1), 4-21.

Hayes, A. F. (2013). Introduction to Mediation, Moderation, and Conditional Process Analysis: A Regression-Based Approach. Guilford Press. Retrieved from http://www.guilford.com/books/Introduction-to-Mediation-Moderation-and-ConditionalProcess-Analysis/Andrew-Hayes/9781609182304

Hennigs, N., Wiedmann, K.-P., \& Klarmann, C. (2012). Luxury brands in the digital ageexclusivity versus ubiquity. Marketing Review St. Gallen, 29(1), 30-35.

Hennigs, N., Wiedmann, K.-P., Klarmann, C., \& Behrens, S. (2015). The complexity of value in the luxury industry: From consumers' individual value perception to luxury consumption. International Journal of Retail \& Distribution Management, 43(10/11), 922-939. 
Holmes, A., Byrne, A., \& Rowley, J. (2013). Mobile shopping behaviour: insights into attitudes, shopping process involvement and location. International Journal of Retail \& Distribution Management, 42(1), 25-39.

Hudders, L. (2011). The luxury trap: the rewarding nature of luxury consumption. Ghent University. Retrieved from https://biblio.ugent.be/publication/2977025/file/4335776

Joy, A., Wang, J. J., Chan, T.-S., Sherry, J. F., \& Cui, G. (2014). M (Art) Worlds: Consumer perceptions of how luxury brand stores become art institutions. Journal of Retailing, 90(3), 347-364.

Kapferer, J.-N. (1998). Why are we seduced by luxury brands? Journal of Brand Management, 6(1), 44-49.

Kapferer, J.-N. (2000). How the Internet impacts on brand management. Journal of Brand Management, 7(6), 389-391.

Kim, A. J., \& Ko, E. (2012). Do social media marketing activities enhance customer equity? An empirical study of luxury fashion brand. Journal of Business Research, 65(10), 1480-1486.

Kim, H., Choi, Y. J., \& Lee, Y. (2015). Web atmospheric qualities in luxury fashion brand web sites. Journal of Fashion Marketing and Management, 19(4), 384-401.

Kim, H., \& Lennon, S. J. (2010). E-atmosphere, emotional, cognitive, and behavioral responses. Journal of Fashion Marketing and Management: An International Journal, 14(3), 412-428.

Kim, J., Fiore, A. M., \& Lee, H.-H. (2007). Influences of online store perception, shopping enjoyment, and shopping involvement on consumer patronage behavior towards an online retailer. Journal of Retailing and Consumer Services, 14(2), 95-107.

Klein, L. R. (2003). Creating virtual product experiences: The role of telepresence. Journal of Interactive Marketing, 17(1), 41-55.

Kluge, P. N., \& Fassnacht, M. (2015). Selling luxury goods online: effects of online accessibility and price display. International Journal of Retail \& Distribution Management, 43(10/11), 1065-1082.

Li, H., Daugherty, T., \& Biocca, F. (2001). Characteristics of virtual experience in electronic commerce: A protocol analysis. Journal of Interactive Marketing, 15(3), 13-30.

Li, H., Daugherty, T., \& Biocca, F. (2002). Impact of 3-D advertising on product knowledge, brand attitude, and purchase intention: The mediating role of presence. Journal of Advertising, 31(3), 43-57.

Liu, Y. (2003). Developing a scale to measure the interactivity of websites. Journal of Advertising Research, 43(02), 207-216.

Mankodiya, K., Martins, R., Francis, J., Garduno, E., Gandhi, R., \& Narasimhan, P. (2013). Interactive shopping experience through immersive store environments. In Design, User Experience, and Usability. User Experience in Novel Technological Environments (pp. 372-382). Springer. Retrieved from http://link.springer.com/chapter/10.1007/978-3-64239238-2_41

Martineau, P. (1958). The personality of the retail store. Retrieved from https://books.google.be/books?hl=nl\&lr=\&id=Rt96wAigg2oC\&oi=fnd\&pg=PA98\&dq= Martineau,+P.+(1958).+The+Personality+of+the+Retail+Store\&ots=pRu5dyDGzR\&sig= j7V_ZhDUNvXB5H-7vlBYfWoX4ao

Okonkwo, U. (2005). Can the Luxury fashion brand store atmosphere be transferred to the Internet. April, Available at: Http://www. Brandchannel. com/images/papers/269_Lux_Goods_Online. Pdf (accessed 6 March).

Okonkwo, U. (2009). Sustaining the luxury brand on the Internet. Journal of Brand Management, 16(5), 302-310. 
Okonkwo, U. (2010). Luxury online: Styles, systems, strategies. Palgrave Macmillan. Retrieved from

https://books.google.be/books?hl=nl\&lr=\&id=MklEVGhuvsgC\&oi=fnd\&pg=PP1\&dq=ok onkwo+2010+luxury\&ots=1059RUFZ16\&sig=B6hjrNMCz0uMF1fWdpoig5CtQUY

Pappas, N. (2016). Marketing strategies, perceived risks, and consumer trust in online buying behaviour. Journal of Retailing and Consumer Services, 29, 92-103.

Phau, I., \& Prendergast, G. (2000). Consuming luxury brands: the relevance of the "rarity principle." The Journal of Brand Management, 8(2), 122-138.

Preacher, K. J., \& Hayes, A. F. (2004). SPSS and SAS procedures for estimating indirect effects in simple mediation models. Behavior Research Methods, Instruments, \& Computers, 36(4), 717-731.

Scarpi, D., Pizzi, G., \& Visentin, M. (2014). Shopping for fun or shopping to buy: Is it different online and offline? Journal of Retailing and Consumer Services, 21(3), 258-267.

Soars, B. (2009). Driving sales through shoppers' sense of sound, sight, smell and touch. International Journal of Retail \& Distribution Management, 37(3), 286-298.

Steuer, J. (1992). Defining virtual reality: Dimensions determining telepresence. Journal of Communication, 42(4), 73-93.

The luxury and cosmetics financial factbook. (2015). Seeking sustainable growth. (pp. 1-72). Retrieved

from http://www.ey.com/Publication/vwLUAssets/EY_Factbook_2015/\$FILE/EY-Factbook2015.PDF

Veblen, T. (1944). The Theory of the Leisure Class. New York: Dover Publications, Inc.

Vigneron, F., \& Johnson, L. W. (1999). A review and a conceptual framework of prestige-seeking consumer behavior. Academy of Marketing Science Review, 1999, 1.

Vigneron, F., \& Johnson, L. W. (2004). Measuring perceptions of brand luxury. The Journal of Brand Management, 11(6), 484-506.

Wiedmann, K.-P., Hennigs, N., \& Siebels, A. (2007). Measuring consumers' luxury value perception: a cross-cultural framework. Academy of Marketing Science Review, 7(7), 333361.

Wiedmann, K.-P., Hennigs, N., \& Siebels, A. (2009). Value-based segmentation of luxury consumption behavior. Psychology \& Marketing, 26(7), 625-651.

Wu, G. (1999). Perceived interactivity and attitude toward web sites. In Proceedings of the conference-American Academy of Advertising (pp. 254-262). American Academy of Advertising. Retrieved

from http://commfaculty.fullerton.edu/mwu/publications/wu1999.pdf

Wu, G., \& Wu, G. (2006). Conceptualizing and measuring the perceived interactivity of websites. Journal of Current Issues \& Research in Advertising, 28(1), 87-104. 
Figure 1: Conceptual Model

\section{FIGURES}

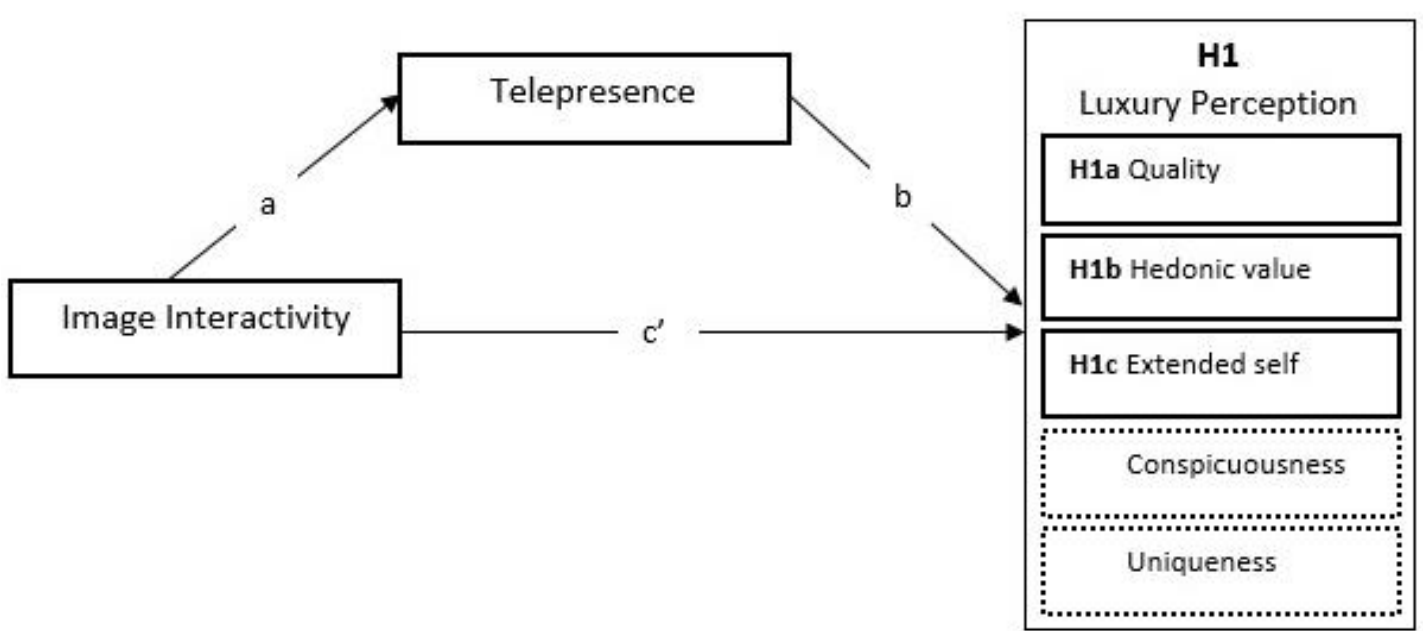

TABLES

Table 1: Telepresence as mediator

\begin{tabular}{|c|c|c|c|c|c|c|c|c|c|c|c|c|}
\hline & $a$ & & & $\boldsymbol{b}$ & & & $c^{\prime}$ & & & $a * b$ & & \\
\hline Luxury perception & .3874 & .1150 & .0009 & .2422 & .0629 & .0002 & -.0439 & 0873 & .6157 & .0938 & .0391 & {$[.0320 ; .1902]$} \\
\hline Quality (H1a) & .3874 & .1150 & .0009 & .2069 & .0663 & .0021 & -.0236 & .1037 & .8201 & .0802 & .0389 & {$[.0285 ; .1934]$} \\
\hline Hedonism (H1b) & .3874 & .1150 & .0009 & .3401 & .0876 & .0001 & -.1050 & .1255 & .4036 & .1317 & .0531 & {$[.0470 ; .2516]$} \\
\hline Extended self (H1c) & .3874 & .1150 & .0009 & .1684 & .0937 & .0740 & .1109 & .1445 & .4438 & .0652 & .0432 & {$[.0042 ; .1861]$} \\
\hline Conspicu & .3874 & .1150 & .0009 & .0889 & .0633 & .1621 & -.1047 & .0940 & .2672 & .0344 & .0279 & {$[-.0082 ; .1061]$} \\
\hline Uniqueness & .3874 & .1150 & .0009 & .3927 & .1037 & .0002 & -.1275 & .1333 & .3399 & .1521 & .0614 & {$[.0577, .3081]$} \\
\hline
\end{tabular}

